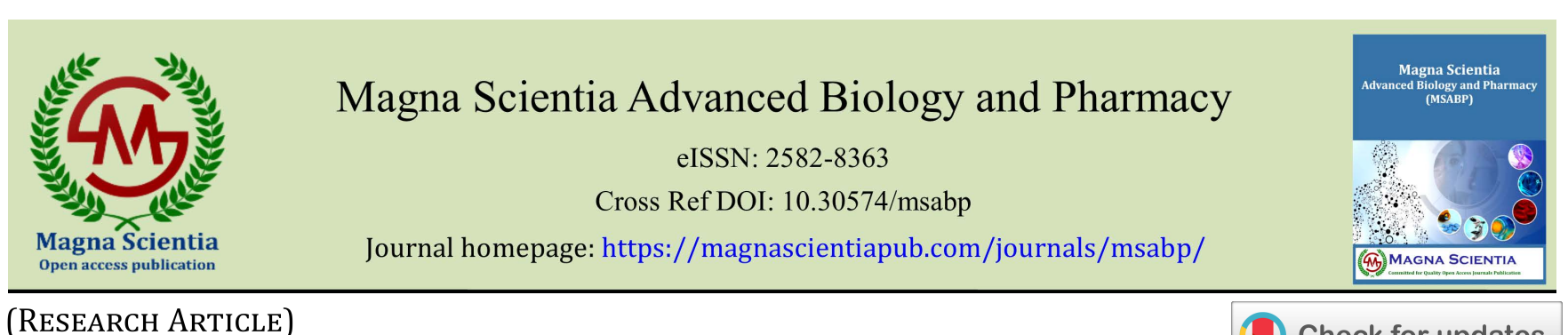

(RESEARCH ARTiClE)

Check for updates

\title{
Seroprevalence of HIV infection among cataract surgery patients in south-east Nigeria: A retrospective cross-sectional study
}

Arinze Anthony Onwuegbuna 1,2, Akunne Ijeoma Apakama 1,2, Chuka Michael Okosa 1,2, Emeka Akujuobi Chianakwalam 2, Miriam-Benigna Chika Amobi 2, Chisom God'swill Chigbo ${ }^{3}$, Ejike Ekene Igboegwu ${ }^{2}$ and George Uchenna Eleje ${ }^{4,5, *}$

${ }^{1}$ Department of Ophthalmology, Nnamdi Azikiwe University, Awka, Nigeria.

${ }^{2}$ Guinness Eye Centre, Onitsha, Nigeria.

${ }^{3}$ Department of Applied Microbiology, Nnamdi Azikiwe University, Awka, Nigeria.

${ }^{4}$ Department of Obstetrics and Gynecology, Faculty of Medicine, Nnamdi Azikiwe University, Awka, Nigeria.

${ }^{5}$ Department of Obstetrics and Gynecology, Nnamdi Azikiwe University Teaching Hospital, Nnewi, Nigeria.

Magna Scientia Advanced Biology and Pharmacy, 2021, 03(02), 001-008

Publication history: Received on 31 July 2021; revised on 04 September 2021; accepted on 06 September 2021

Article DOI: https://doi.org/10.30574/msabp.2021.3.2.0039

\begin{abstract}
Background: Human Immunodeficiency Virus remains an important cause of morbidity and mortality especially in subSaharan Africa. Despite the availability of highly active antiretroviral therapy, many people with this disease still present with its ocular complications. Cataracts remain the commonest reason for blindness in Nigeria and globally. The prevalence of HIV infection among cataract patients in south east Nigeria has remained unknown.
\end{abstract}

Objectives: To determine the prevalence of human immunodeficiency virus among cataract patients in south east Nigeria.

Materials and Methods: This was a retrospective cross-sectional study. The case files of all who had cataract surgery between September 1'st, 2020 to March 31 st, 2021 at City of Refuge Specialist Eye Clinic Onitsha, Nigeria was obtained from the Medical Record Department of the hospital to extract relevant information and demographic data. The outcome measures included the prevalence of HIV, as well as the gender and the age of affected cataract patients. Data was analyzed using SPSS 26.0 IBM Corporation. Fisher's exact test was performed for categorical data, and Student's t-test was applied to continuous variables depending on their distribution. A p value of $<0.05$ was considered statistically significant.

Results: In this study, 423 participants who underwent cataract surgery were included for analysis of which 16 were HIV positive. The overall seroprevalence of HIV among the study population was $3.78 \%$ with HIV prevalence showing the female to male ratio of $1: 1$. Up to $70.81 \%$ of the patients were at least 60 years of age. Although there was a statistically significant difference between the prevalence of HIV and seasonal presentation $(\mathrm{p}=0.015)$, there was no statistically significant relationship between the participants age and gender $(p=0.195)$, prevalence of HIV and the participants' age categories ( $\mathrm{p}=0.149)$ or participants' settlements $(\mathrm{p}=0.219)$.

Conclusion: The prevalence of HIV among cataract patients in this study was 3.78\%. This study confirms that HIV infections are an important public problem among cataract patients in Nigeria. Our findings draw attention to the significant burden HIV has on cataract surgery in Nigeria. We recommend advocacy for the national policymakers to initiate HIV tests in routine ophthalmology services.

\footnotetext{
${ }^{*}$ Corresponding author: George Uchenna Eleje

Department of Obstetrics and Gynecology, Faculty of Medicine, Nnamdi Azikiwe University, Awka, Nigeria.
} 
Keywords: Cataract; HIV; Ophthalmology; Prevalence; Policymaker

\section{Introduction}

Human Immunodeficiency Virus (HIV) infection remains an important cause of morbidity and mortality, especially in sub-Saharan Africa [1]. Many years after recording its first HIV case, the burden of HIV in Nigeria still continues to be high [2]. Though a blood borne disease transmitted through sharing of contaminated needles, syringes and other injecting equipment, HIV is also transmitted through unprotected anal or vaginal sex and through oral sex. Unsafe organ transplants, blood transfusions or blood products increase the risk of HIV infection. Health workers who attend to HIV patients are also at risk of contracting HIV infection [3].

The prevalence of HIV infection is affected by many factors and varies from country to country and even within the same country. Some of these factors affecting HIV prevalence include religious beliefs, cultural practices, access to Highly Active Antiretroviral Therapy (HAART), poor urban dwelling, malnutrition and having multiple sexual partners [4].

Cataract is still the leading cause of avoidable blindness worldwide with Nigeria having a high cataract burden. According to the Nigeria National Blindness and Visual Impairment survey, cataract remains the commonest cause of blindness in Nigeria [5]. About 10 million cataract surgeries are performed globally each year, making cataract surgery not only one of the commonest surgical procedures performed globally, but also one of the most cost effective [6]. This high volume of cataract surgeries increases the risk of contracting blood borne diseases like HIV from patients by eye care staff, especially the surgical team. The availability of HAART has helped many HIV positive patients to overcome deadly opportunistic infections thereby living longer and adding to the cataract burden This risk of transmission is even higher where the seroprevalence of HIV cataract patients is not known, especially in low income countries like Nigeria with high burden of both HIV and cataract [7]. Therefore, awareness of HIV seroprevalence of booked cataract patients will help the cataract surgical team to engage universal precautions against HIV infections.

Patients with HIV often present with ocular diseases. These include cataract which could be complicated, uveitis, HIV retinopathy, squamous cell carcinoma, and herpes zoster ophthalmicus. Other HIV associated ocular diseases are Kaposi sarcoma, cytomegalovirus (CMV) retinitis and retinal detachment [7].

Most cataract services are usually offered within eye hospitals or community outreaches. Majority of cataract surgeries are done under local anesthesia [8]. These include topical anesthesia and periocular injection of local anesthetic. Periocular injections carry the risk of needle stick injuries especially if the one giving the injection is inexperienced or the patient is uncooperative. Handling and exchange of very sharp micro-surgical instruments in the course of the cataract surgery on HIV positive patients portend danger to the surgical team. Eye care staff is also at risk of HIV infection while cleaning HIV contaminated instruments and during the disposal of HIV contaminated biomedical waste. Biometry and contact tonometry are frequent preoperative evaluations for cataract patients, also carry the risk of HIV infection [3].

The risk of HIV infection is therefore higher when the HIV sero-status of patients undergoing cataract surgeries is unknown. Moreover, outcomes of cataract surgeries are also influenced by HIV seropositivity. This means that cataract surgery in HIV patients will require special considerations in order to protect the eye care staff, protect other patients undergoing cataract surgeries at the same time and also to achieve a good outcome [9]. The objectives of this study were to assess the seroprevalence of HIV among cataract patients, to determine the age, gender and other demographic characteristics of HIV cataract patients who had cataract surgery, and to assess the significance of routine HIV screening before carrying out cataract surgery.

\section{Material and methods}

\subsection{Study design}

A cross-sectional retrospective study.

\subsection{Study population}

The study was conducted among patients that underwent cataract surgery at City of Refuge Specialist Eye Clinic, Onitsha, Nigeria. 


\subsection{Study site}

City of Refuge Specialist Eye Clinic, Onitsha. It has consultant ophthalmologists, optometrists and ophthalmic nurses, laboratory scientists among other health workers. It serves as a referral centre for cataract surgeries for eye clinics within Anambra, parts of Imo, Enugu, Abia, Ebonyi and Delta states.

\subsection{Inclusion criteria}

All cataract patients who underwent cataract surgery between 1st September 2020 to March 31st 2021 at City of Refuge Specialist Eye Clinic, Onitsha, Anambra state, Nigeria.

\subsection{Exclusion criteria}

Patients who underwent surgery other than cataracts were excluded.

\subsection{Sample size determination}

The sample was calculated using a single population proportion with the following assumptions: an expected prevalence of $50 \%$, margin of error of $5 \%$, at $95 \%$ confidence level. The calculated sample size was 423 . However, a total of 423 cataract patients, who were between 20 and 90 years old and eligible for the study, were identified during and their case files retrieved. Relevant data was extracted.

\subsection{Sample technique}

Non-random sampling technique was employed.

\subsection{Study outcome Measures}

The prevalence of HIV, as well as the gender and the age of affected cataract patients.

\subsection{Procedures involved}

The theatre records were reviewed to identify patients that underwent only cataract surgeries during the study period. These patients' case records were then retrieved from the hospital record department. The patients' socio-demographic data, HIV sero status and indication for the cataract surgery were retrieved and analyzed.

\subsection{Sample Collection and Detection of Antibody for HIV}

HIV was tested using commercially available rapid test kits following the manufacturer's protocol and Nigerian national HIV test algorithm. The national HIV test algorithm involves three tests to confirm HIV sero-positivity. According to the algorithm, Alere Determine (Alere Medical Co. Ltd., Matsudo, Japan) was the first screening test and any positive samples in Alere Determine need re-confirming with second test Uni-Gold Recombigen ${ }^{\circledR}$ (Trinity Biotech, Ireland) to be positive. Samples giving discordant results in the two tests (Alere Determine and Uni-Gold Recombigen ${ }^{\circledR}$ ) were retested using tiebreakers STAT-PAK (Chembio Diagnostic Systems, Inc., USA). Patients who were positive on the third test were also considered positive. Strict national guidelines, manufacturer's direction, and standard operational procedures were followed for each test procedure to ensure quality.

\subsubsection{Data Quality Control}

Data extraction was conducted using a pre-tested structured review proforma. Data collection was performed by two trained medical professionals under the principal investigator's supervision. The clarity and extensiveness of data were checked daily by the principal investigator.

\subsubsection{Data Processing and Statistical Analysis}

All collected data were entered and cleaned by Excel spreadsheet. The cleaned data were exported to SPSS version 26.0 statistical software for analysis. Continuous variables were presented using mean, median and standard deviation, while categorical variables were described by frequency and proportion; and presented using tables and figures. Data was analyzed using SPSS 26.0 IBM Corporation. Fisher exact test was performed. A p value of $<0.05$ was considered statistically significant. 


\subsection{Ethical consideration}

The study protocol was reviewed and approved by the Chukwuemeka Odumegwu Ojukwu University Teaching Hospital Ethics Committee (Reference No. COOUTHWU/CMAC/ETH.C/VOL.1/FN:04/0090 and date of ethical approval obtained was 29/04/2021). Written informed consent was sought from each study participant, but for those who could not write and read; oral informed consent was also obtained. The confidentiality of the collected data was assured during data collection and anonymity of the study participants was maintained during analysis.

\section{Results}

In this study, 423 participants who underwent cataract surgery between September 2020 and March 2021 were included for analysis of which $16(3.78 \%)$ were HIV positive. The prevalence of HIV among cataract patients was $3.78 \%$. Three hundred and ninety-one participants out of the 423 revealed their ages.

Table 1 Distribution of age and gender among the study participants

\begin{tabular}{|c|c|c|c|}
\hline Age (years) & Total freq (\%) $(\mathbf{n = 3 9 1 )}$ & \multicolumn{2}{|c|}{ Gender (\%) } \\
\hline & & Female $(\mathbf{n = 2 0 0 )}$ & Male $(\mathbf{n = 1 9 1 )}$ \\
\hline 15-29 years & $9(2.30)$ & $2(1.0)$ & $7(3.7)$ \\
\hline 30-44 years & $20(5.10)$ & $13(6.5)$ & $7(3.7)$ \\
\hline 45-59 years & $85(21.68)$ & $47(23.5)$ & $38(19.9)$ \\
\hline 60-74 years & $210(53.71)$ & $102(51.0)$ & $108(56.5)$ \\
\hline 75-89 years & $62(15.82)$ & $32(16.0)$ & $30(15.7)$ \\
\hline$>90$ years & $5(1.28)$ & $4(2.0)$ & $1(0.5)$ \\
\hline Mean Age $( \pm S T D)$ & $63.85 \pm 12.75$ & $63.66 \pm 12.28$ & $64.05 \pm 13.29$ \\
\hline
\end{tabular}

Table 2 Prevalence of HIV distribution in males and females

\begin{tabular}{|c|c|c|c|}
\hline \multirow[t]{2}{*}{ Viral disease } & \multirow[t]{2}{*}{ Total freq (\%) } & \multicolumn{2}{|c|}{ Gender (\%) } \\
\hline & & Female & Male \\
\hline \multicolumn{4}{|l|}{ HIV } \\
\hline Positive & $16(3.8)$ & $8(3.6)$ & $8(4.0)$ \\
\hline No disease & $406(96.2)$ & 215 (96.4) & $191(96.0)$ \\
\hline Fischer's exact ( $p$ ) & $0.054(0.816)$ & & \\
\hline
\end{tabular}

Table 3 Prevalence of HIV distribution in among different age categories

\begin{tabular}{|c|c|c|c|c|c|c|c|}
\hline \multirow[t]{2}{*}{ Viral disease } & \multirow[t]{2}{*}{ Total freq (\%) } & \multicolumn{6}{|c|}{ Age category (years) (\%) } \\
\hline & & $15-29$ & $30-44$ & $45-59$ & $60-74$ & $75-89$ & $>90$ \\
\hline \multicolumn{8}{|l|}{ HIV } \\
\hline Positive & $15(3.8)$ & 0 & $3(15.0)$ & $4(4.7)$ & $6(2.8)$ & $2(3.2)$ & 0 \\
\hline No disease & 377 (96.2) & $9(100)$ & $17(85.0)$ & $81(95.3)$ & $205(97.2)$ & $60(96.8)$ & $5(100)$ \\
\hline$\chi^{2}$-value $(p)$ & $8.135(0.149)$ & & & & & & \\
\hline
\end{tabular}


Table 4 Prevalence of HIV distribution among rural, urban and semi-urban settlements

\begin{tabular}{|l|c|c|c|c|}
\hline Viral disease & Total freq (\%) & \multicolumn{3}{|c|}{ Location (\%) } \\
\hline & \multicolumn{5}{|c|}{ Rural } & Semi-urban & Urban \\
\hline HIV & $7(1.9)$ & $4(3.4)$ & $1(3.6)$ & $2(0.9)$ \\
\hline Positive & $362(98.1)$ & $114(96.6)$ & $27(96.4)$ & $221(99.1)$ \\
\hline No disease & $3.033(0.219)$ & & & \\
\hline$\chi^{2}$-value $(p)$ & &
\end{tabular}

Table 5 Prevalence of HIV across different months of the year (September-March)

\begin{tabular}{|l|c|c|c|}
\hline Viral disease & Total freq (\%) & \multicolumn{2}{|c|}{ HIV (\%) } \\
\hline & & No disease $(\mathrm{n}=407)$ & Positive $(\mathrm{n}=16)$ \\
\hline December & $59(13.9)$ & $59(14.5)$ & 0 \\
\hline February & $68(16.1)$ & $67(16.5)$ & $1(6.2)$ \\
\hline January & $61(14.4)$ & $55(13.5)$ & $6(37.5)$ \\
\hline March & $68(16.1)$ & $67(16.5)$ & $1(6.2)$ \\
\hline November & $59(13.9)$ & $57(14.0)$ & $2(12.5)$ \\
\hline October & $53(12.5)$ & $48(11.8)$ & $5(31.2)$ \\
\hline September & $55(13.0)$ & $54(13.3)$ & $1(6.2)$ \\
\hline TOAL & $423(100)$ & $407(100)$ & $16(100)$ \\
\hline
\end{tabular}

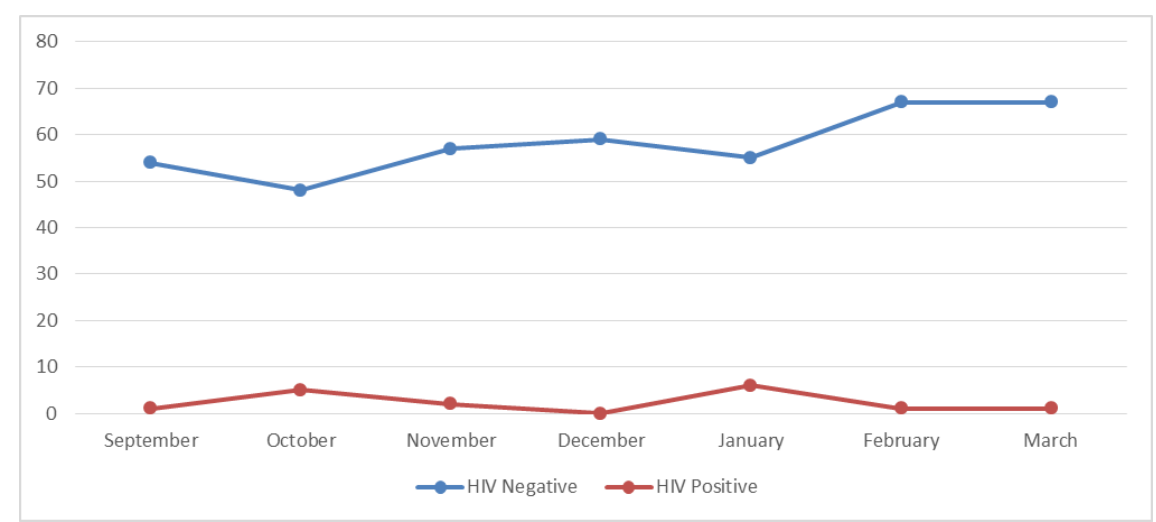

Figure 1 Distribution of HIV across different months of the year (September-March)

Table 1 shows the distribution of age and gender of the participants. Up to $70.81 \%$ of the patients were at least 60 years of age. Both male and females are equally distributed. There was no statistically significant relationship between the participants age and gender $(\mathrm{p}=0.195)$. Regarding gender, the HIV prevalence shows the female to male ratio of $1: 1$. This is shown in Table 2.

The prevalence of HIV distribution among different age categories is shown in Table 3. There was no significant difference between the prevalence of HIV and the participants' age categories $(\mathrm{p}=0.149)$. 
Table 4 shows the prevalence of HIV distribution among rural, urban and semi-urban dwellers. The prevalence of HIV was not influenced by the participants' settlements $(\mathrm{p}=0.219)$.

Table 5 and figure 1 show the prevalence of HIV across different months of the year (September-March). There was a statistically significant difference between the prevalence of HIV and the different months of the year presentation of the cases $(\mathrm{p}=0.015)$.

\section{Discussion}

This study represents the first published study of HIV-positive patients that exclusively underwent cataract surgery in a hospital setting in Nigeria, to the authors' knowledge. This study found that the prevalence of HIV among cataract patients was $3.78 \%$. There was a significant difference between the prevalence of HIV and the different months of the year presentation of the cases $(\mathrm{p}=0.015)$.

As revealed in this study, the prevalence of HIV among cataract patients in this study was $3.78 \%$. This finding was similar to a study conducted in Gabon that found HIV prevalence of $4.6 \%$ among people who underwent cataract surgery during humanitarian surgical mission [10]. However, published values continued to be high compared to $0.09 \%$ reported in the literature by Rawri et al [11] and $0.35 \%$ by Ambastha et al [12]. In a previous Nigerian study by Ezegwui et al aimed at highlighting the need to offer HIV voluntary counseling and testing services to ophthalmic surgery patients so that seropositive patients can be identified early and managed appropriately, an HIV seroprevalence of 3.0\% was recorded [13]. Additionally, our findings were also substantiated by another previous Nigerian study by Alhassan et al, aimed at determining the proportion of patients for eye surgery who were HIV/AIDS seropositive at the National Eye Centre, Kaduna, Nigeria, whose prevalence of HIV was $0.2 \%$ [14].

The clinical implications of the current study is that ocular comorbidities can occur in HIV positive patients as well as in HIV negative subjects [15]. For instance, in a previous study, the HIV positive patients with uveitis prior to surgery improved less $(p=0.046)$ than HIV negative participants $(p<0.001)[15]$. The associated risk factor for HIV infections among cataract patients was month of the year which appears to be commoner in the dry season. Thus, routine HIV voluntary counseling and testing services are encouraged for all ophthalmic surgery patients so that seropositive patients can be recognized and prompt fitting management initiated. More recently, modified small-incision cataract surgery with posterior chamber lens implantation has been suggested as a surgical technique suitable for cataract surgery in regions with a high prevalence of HIV infection [16].

One of the lingering concerns of ophthalmologists operating on cataract patients with HIV infection has been risk of viral transmission during the procedure. However, despite the concerns, HIV transmission from patients to operating surgeons is tremendously rare [17]. Standard precautions to prevent occupational exposure to HIV and other infectious pathogens in the healthcare scenery and during surgery have been highly effective with only one healthcare worker confirmed contracting HIV from 2000 to 2013 [18]. These data reinforce the need for continuing and further education of eye care providers and staff regarding the usefulness of standard precautions and low risk of HIV transmission.

Although this current study brings very important evidence on the burden of HIV among cataract patients and forwarded recommendation for policy makers, it has its own limitations. The main limitation of the study was the study design which makes the study result not to be generalized to the general population. The key limitations of this study are related to the patients' population and number of cataract procedures performed in the single center study site among HIV positive participants. These limitations may impact the generalizability of findings. The overall number of HIV positive subjects was small, so findings should be interpreted cautiously. Participant responses may have been influenced by the interviewers' own biases and the presence of the interviewer may have in turn affected the participant response. There may have also been an issue of recall bias among participants. However, efforts were made to use trained research assistants who were well versed in the research methods, knowledgeable in how to probe for more accurate recall, and comfortable with the sensitivities of the subject matter. Despite these, the study can be used for better planning of HIV among cataract patients and endorse the initiation of HIV tests in routine ophthalmology services.

\section{Conclusion}

The prevalence of HIV among cataract patients in this study was 3.78\%. This study confirms that HIV infections are an important public health problem among cataract patients in Nigeria. Many patients living with HIV infection may be appropriate candidates for cataract operation. The associated risk factor for HIV infection among cataract patients was month of the year which appears to be commoner in the dry season. Hence, this study suggested the need for structured 
education of the population for HIV prevention, and recommended advocacy for the national policymaker to initiate HIV tests in routine ophthalmology services. We also suggest that screening for viral markers should be made mandatory before ocular surgeries so that early detection and treatment of patients can be done and risk of horizontal spread is minimized.

\section{Compliance with ethical standards}

\section{Acknowledgments}

The authors would like to thank all the patients whose data were used in the study. We also thank all the staff of the hospital involved in this study.

The authors received no specific funds for this work.

The data used to support the findings of this study are available from the site publicly.

\section{Disclosure of conflict of interest}

The authors declare that they have no competing interests.

All authors have made substantial contributions to: conception and design of the study, or acquisition of data, or analysis and interpretation of data; drafting the article or revising it critically for important intellectual content; and final approval of the version submitted. This manuscript has not been submitted for publication in another journal.

AA Onwuegbuna, EA Chianakwalam, and GU Eleje were involved in the overall conceptual design and implementation of the project, and overall revision of the manuscript. MC Amobi, AI Apakama, CM Okosa, EE Igboegwu and CG Chigbo were involved in the writing of this manuscript and overall revision. The authors read, approved the final manuscript and agreed to be accountable for all aspects of the work.

\section{Statement of ethical approval}

Ethical approval was obtained from Chukwuemeka Odumegwu Ojukwu University Teaching Hospital, Amaku, Awka, Nigeria, with registration number: COOUTH/CMAC/ETH.C/vol.1/FN: 04/009 (approval date: April 29, 2021).

\section{Statement of informed consent}

Informed consent was obtained from all individual participants included in the study.

\section{References}

[1] Jian-Yu E, Wang Z, Ssekasanvu J, Munoz B, West S, Ludigo J, et al. Visual Impairment and Eye Diseases in HIVinfected People in the Antiretroviral Therapy (ART) Era in Rakai, Uganda. Ophthalmic Epidemiol. 2020.

[2] Buhari M. New survey results indicate that Nigeria has an HIV prevalence of. 2021; (March 2019): 14-6.

[3] Ravikiran P, Nageswara Rao U. Seroprevalence of HIV, Hepatitis B and Hepatitis C infections in cataract surgery patients. IP Int J Ocul Oncol Oculoplasty. 2020; 6(3): 183-6.

[4] Awofala AA, Ogundele OE. HIV epidemiology in Nigeria. Saudi J Biol Sci [Internet]. 2018; 25(4): 697-703.

[5] Wang W, Yan W, Fotis K, Prasad NM, Lansingh VC, Taylor HR, et al. Cataract surgical rate and socioeconomics: A global study. Investig Ophthalmol Vis Sci. 2016; 57(14): 5872-81.

[6] Dineen B, Gilbert CE, Rabiu M, Kyari F, Mahdi AM, Abubakar T, et al. The Nigerian national blindness and visual impairment survey: Rationale, objectives and detailed methodology. BMC Ophthalmol. 2008; 8: 1-14.

[7] Saini N, Hasija S, Kaur P, Kaur M, Pathania V, Singh A. Study of prevalence of ocular manifestations in HIV positive patients. Nepal J Ophthalmol. 2019; 11(1): 11-8.

[8] Shah R. Anesthesia for cataract surgery: Recent trends. Oman J Ophthalmol. 2010; 3(3): 107.

[9] Akpuh N, Ajayi IO, Adebowale A, Idris Suleiman H, Nguku P, Dalhat M, et al. Occupational exposure to HIV among healthcare workers in PMTCT sites in Port Harcourt, Nigeria. BMC Public Health. 2020; 20(1): 1-8. 
[10] Mba AA, Anyunzoghe E, Anyunzoghe E, Itoudi BP, Ndjillekissa NS, Agaya C, Mengome E. Seroprevalence of HIV, Hepatitis B and C Viruses Infections among Candidates for Cataract Surgery. Open Journal of Ophthalmology. 2019; 9 (2): 47-53.

[11] Rewri P, Sharma M, Vats DP, Singhal A. Seroprevalence, risk associations, and cost analysis of screening for viral infections among patients of cataract surgery. Indian J Ophthalmol. 2018 Mar; 66(3): 394-399.

[12] Ambastha A, Kusumesh R, Bhasker G. Why Should Viral Markers Be Mandatory in Ocular Surgeries: A Hospital Based Retrospective Study. J Clin Diagn Res. 2016 Oct; 10(10): LC09-LC11.

[13] Ezegwui IR, Akaraiwe NN, Onwasigwe EN. HIV seroprevalence in ophthalmic surgery patients at ESUT Teaching Hospital Enugu. Niger J Med. Apr-Jun 2012; 21(2): 194-5.

[14] Alhassan MB, Unung P, Adejor G. HIV and HBsAg Seropositivity Amongst Patients Presenting for Ocular Surgery at a Tertiary Eye Care Hospital in Nigeria. Open Ophthalmol J. 22 Mar 2013; 7: 18-9.

[15] Accorinti M, Cecere M, Scala A, Pirraglia MP. Cataract Surgery in HIV Seropositive Patients: Long-Term FollowUp. Ocul Immunol Inflamm. 2019; 27(3): 435-446.

[16] Giles K, Domngang C, Nguefack-Tsague G, Come EM, Wiedemann P. Modified Small Incision Cataract Surgery and Intraocular Lens Implantation in HIV Patients. Ophthalmol Eye Dis. 9 Nov 2015; 7: 35-7.

[17] Tisdale CS, Justin GA, Wang X, Chu X, Carlton DK, Okulicz JF, et al. Infectious Disease Clinical Research Program HIV Working Group. Refractive surgery in the HIV-positive U.S. Military Natural History Study Cohort: complications and risk factors. J Cataract Refract Surg. Nov 2019; 45(11): 1612-1618.

[18] Joyce MP, Kuhar D, Brooks JT. Notes from the field: occupationally acquired HIV infection among health care workers - United States, 1985-2013. MMWR Morb Mortal Wkly Rep. 9 Jan 2015; 63(53): 1245-6. 